\title{
EDUCAÇÃO FÍSICA E ALFABETIZAÇÃO: EM BUSCA DE INTERLOCUÇÃO
}

Rodrigo Rodrigues Menegon, Márcia Regina Canhoto de Lima, José Milton Lima, Joyce Cristina Claro Menoti.

Universidade Estadual Paulista - UNESP, Programa de Pós-Graduação em Educação. Financiamento: PROEX. E-mail: rrmenegon10@gmail.com.

\section{RESUMO}

Este ensaio evidenciou que a alfabetização não se limita ao domínio da linguagem oral/escrita. 0 objetivo buscou analisar e descrever a importância que a Educação Física escolar tem no processo de alfabetização. A metodologia caracterizou-se como um estudo qualitativo de cunho descritivointerpretativo. A pesquisa foi realizada em uma Escola Municipal, e contou com a participação dos estagiários e dos monitores vinculados ao projeto de extensão, a participação das professoras e das tutoras da sala e seus respectivos alunos. Os resultados possibilitaram afirmar que a linguagem corporal, trabalhada nas aulas de Educação Física, quando bem direcionadas e empregadas de maneira significativa, corroboram com o desenvolvimento das capacidades física e, consequentemente, no processo de ensino/aprendizagem dos alunos. Portanto, um processo de alfabetização significativo para as crianças não se restringe apenas ao ato de ler e escrever; é preciso, valorizar e trabalhar as múltiplas linguagens existentes no contexto, possibilitando assim, um processo de formação integral.

Palavras-chave: Educação Física Escolar, Linguagem Corporal, Linguagem Oral, Linguagem Escrita, Alfabetização.

\section{PHYSICAL EDUCATION AND LITERACY : IN SEARCH INTERLOCUTION}

\begin{abstract}
This trial showed that literacy is not limited to the oral / written language domain. The aim was to examine and describe the importance of Physical Education has in the literacy process. The methodology was characterized as a qualitative study of descriptive and interpretative. The survey was conducted in a Municipal School, and featured the participation of trainees and monitors linked to the extension project, the participation of teachers and room tutors and their students. The results allowed to state that the body language, worked in physical education classes, when properly targeted and used in a meaningful way, corroborate the development of physical capabilities and consequently the teaching / learning process of students. Therefore, a significant literacy process for children is not restricted to the act of reading and writing; you need, value and work multiple existing languages in the context, thus enabling a process of integral formation.
\end{abstract}

Keywords: Physical Education, Body Language, Oral Language, Written Language, Literacy. 


\section{INTRODUÇÃO}

Essa pesquisa, é decorrente da minha inserção no Curso de Licenciatura em Educação Física da FCT/UNESP de Presidente Prudente. Desde o ingresso na Universidade, procurei qualificar minha formação, com o objetivo de expandir e aprimorar meus conhecimentos. Mesmo não sabendo que caminho seguiria dentro de uma área tão vasta como é a Educação Física, a única certeza que tinha, era a vontade de trabalhar com o ensino.

O interesse pela temática abordada no decorrer deste trabalho se deu em função da minha participação em dois projetos de extensão universitária denominados "Educação Física e as linguagens do universo infantil" e "Educação Física no Ensino Fundamental".

Esses projetos de extensão que estão voltados à área da Educação Física Escolar, e do qual participei desde meu ingresso na Universidade, alicerçam-se na Lei de Diretrizes e Bases da Educação Nacional (1996), e buscam garantir a Educação Física como um componente curricular obrigatório, e trazem, dentre seus objetivos mais explícitos, a possibilidade de proporcionar aos alunos aulas de Educação Física. Assim, as atividades desenvolvidas nos projetos buscam oferecer a esses estudantes uma gama de atividades que contemplem $\mathrm{o}$ desenvolvimento harmônico dos aspectos físicos/motores, cognitivos, afetivos e sociais.

É sabido que a questão do analfabetismo no Brasil, é um tema que apresenta dissabores na atualidade. Nesse sentido, recai sobre o educador uma maior responsabilidade, frente aos métodos didáticos pedagógicos apresentados à escola. Uma educação de qualidade, na contemporaneidade, é aquela em que a escola consegue promover, a todos, um domínio geral dos conhecimentos, proporcionando o desenvolvimento das capacidades cognitivas, afetivas e motoras, que são indispensáveis para sanar as necessidades sociais e individuais dos alunos (LIBÂNEO, 2003).

Desta forma, os processos de alfabetização tem se tornado um questionamento bastante discutido pelos que se preocupam com a educação. Kramer e Abramovay (1985) descrevem a alfabetização como um processo ativo de leitura e interpretação, onde a criança não só decifra o código escrito, mas também o compreende, estabelece relações, interpreta. Deste modo, alfabetizar não se restringe à aplicação de rituais repetitivos de escrita, leitura e cálculo, mas tem início no momento da própria expressão, quando as crianças falam de sua realidade e identificam os objetos que estão ao seu redor; ou seja, alfabetização é um processo de construção. 
Ainda nesta mesma linha de pensamento, Ferreiro (2000), compreende que a alfabetização faz parte de um processo, amplo e complexo. É um processo que vai além da superficial aquisição do código gráfico, a significação do mesmo. É perceptível, ainda, que a escola impõe para os alunos situações de ensino/aprendizagem que não condizem com sua realidade, suas culturas e a faixa etária.

A alfabetização, segundo Freire (2001) é considerada um processo contínuo às inerentes invenções e reinvenções; uma investigação contínua, ou seja, demanda de criatividade, significação e resignificação. Por ser a educação a base desse processo, ela deve transformar o ser humano num ser crítico e persistente com rumo a melhoria da sua qualidade de vida. Nesta perspectiva, a escola tem o dever priorizar a humanização como tarefa contínua e criativa, levando em conta a visão crítica e dinâmica do ser humano; deve se auto-avaliar e ser autocrítico e dar condições para isso.

A alfabetização, muitas vezes, acontece por meio de metodologias limitadas ao ato mecânico do ler e escrever; já o letramento, além de abordar a capacidade de esclarecer letras e fonemas, responde às demandas sociais. Se uma criança está inserida numa ampla cultura letrada, certamente ela terá uma influência muito positiva na evolução de seu aprendizado em séries posteriores. Entretanto, é preciso enfatizar também as relações interpessoais, as vivências sociais, vinculando essa aprendizagem ao contexto histórico-cultural da criança. Um processo de alfabetização fundamentado, rico em cultura e inclusões sociais, respeitando e aproveitando as vivências individuais de cada aluno, contribui para o desenvolvimento integral de um cidadão (GARCIA, 1998).

Com isso, podemos entender que o conceito de alfabetização está proposto a mudanças, de acordo com as épocas, as culturas, a chegada das tecnologias e demais inovações, tornando-se por isso, necessário que o professor esteja aberto às mudanças que ocorrem em seu tempo (FERREIRO, 2003).

Então, ao inserir uma criança no ambiente escolar, ela não vai dispor somente da fala, mas sim, de diversos comportamentos motores que, independente de sua dimensão prática e funcional, também representam uma face de sua própria linguagem. O corpo, assim como as palavras, é capaz de se comunicar, de agir e de transmitir o pensar; modos que se fazem presentes no mundo, responsáveis pela interação com os demais.

Entretanto, a prática de Educação Física na escola não deve ser identificada como conteúdo dispensável à formação do aluno ou prática educativa. Infelizmente, na 
visão de alguns profissionais de ensino que deixam para segundo plano a importância desta área de ensino no desenvolvimento da aprendizagem, vem sendo excluída da Matriz Escolar, especialmente nos anos iniciais da Educação Básica. Se assim o for, corre o risco de se mostrar com um caráter discriminatório em relação ao contexto escolar, desconsiderando quaisquer aspectos positivos da prática da Educação Física, optando pela supressão da disciplina em algumas escolas, como se sua prática fosse dispensável.

Essa constatação, foi registrada por Federici (2004), quando discute a problemática da disciplina e as avaliações antecipadas de muitas pessoas sobre a Educação Física escolar , e apresenta que “... o senso comum é forte influência na formação de opiniões, as mais diversas, no nosso meio" (FEDERICl, 2004, p. 1). Já, Macedo e Antunes (1999), enfatizam ainda, que os professores de Educação Física muitas vezes são considerados, simples e mero executores com baixo reconhecimento profissional, marginalizados pelos próprios colegas de outras disciplinas curriculares.

Porém, no decorrer dos últimos anos, com a implantação de algumas leis nacionais como, LDBEN (1996) e PCNs (1997), é notável perceber um avanço nos parâmetros sociais voltados à concepção de corpo. A partir daí, a Educação Física escolar tende a vir a acompanhar as tendências, passando a refletir e reformular-se na formação do indivíduo integral, envolvendo o corpo e a mente. A partir da Educação Infantil e dos primeiros anos do Ensino Fundamental I, esse contexto deve-se tornar efetivamente solidificado, que poderá servir de alicerce para a formação de um indivíduo completo.

Diante deste contexto, a Educação Física, por ser um componente curricular obrigatório conforme a Lei de Diretrizes e Bases da Educação Nacional (1996), fundamentada pelos Parâmetros Curriculares Nacionais (1997) que relaciona esta disciplina a cultura corporal de movimento, e com as transformações que ocorrerão no decorrer dos anos, ela tende a ser mais um instrumento relevante e importante na vida da criança quanto ao seguimento da sua alfabetização.

No que se refere à contribuição das diferentes áreas de conhecimento, os Parâmetros Curriculares Nacionais para o Ensino Fundamental aponta, ainda, em relação à Educação Física, que, "é a área do conhecimento que introduz e integra os alunos na cultura corporal do movimento, com finalidades de lazer, de expressão de sentimentos, afetos e emoções, de manutenção e melhoria da saúde" (PCNs 1997 p.62).

Embasado, ainda, nos Parâmetros Curriculares Nacionais de (1997), o 
movimento é uma dimensão do desenvolvimento e da cultura e, ao se tratar de criança, podemos afirmar que a linguagem mais natural e fácil de ser interpretada por elas, se dá por meio do movimento e da ludicidade. Linguagens das quais fazem com que as crianças vivenciem, aprendam e corrijam suas dificuldades e falhas, permitindo uma alfabetização tranquila e segura, além de propiciar segurança para a escola e satisfação para os pais.

Partindo desse pressuposto, acreditamos que as aulas de Educação Física possibilitem a abertura de novos espaços para o diálogo e aprendizagem, criando mecanismos e estratégias para que as crianças possam se desenvolver integralmente e viver melhor. Por meio desta linguagem, as aulas se transformarão num espaço rico de vivências significativas, de descobertas, criações, de produção de conhecimento e cultura e, principalmente, de reflexão crítica sobre a experiência, contribuindo para seu processo de formação humana.

Neste sentido, a Educação Física escolar pode ser reconhecida por seu caráter socializador, que tem no movimento um grande aliado no que diz respeito ao desenvolvimento, tanto físico quanto intelectual das crianças. Por meio de sua prática pedagógica, eficiente e comprometida com o desenvolvimento, torna-se um importante instrumento capaz de auxiliar no processo de ensino aprendizagem dos alunos em diferentes dimensões.

Diante do exposto, os objetivos desta pesquisa foram os investigar, analisar e descrever a importância e os benefícios que a prática de Educação Física no ambiente escolar tem proporcionado no processo de alfabetização dos alunos do primeiro ano do Ensino Fundamental I, de uma Escola Municipal, na ótica dos monitores e estagiários da disciplina de Educação Física e de outros professores do cotidiano escolar.

\section{METODOLOGIA}

A pesquisa fundamenta-se em um método qualitativo de cunho descritivointerpretativo que pode ser delineado por quatro procedimentos, sendo eles, descrição, registro, análise e interpretação de fenômenos atuais (LAKATOS, 1990). A pesquisa foi realizada em uma Escola municipal de Ensino infantil e Fundamental I, situada na cidade de Presidente Prudente SP, onde é proposta a realização de um dos projetos de extensão voltado à Educação Física Escolar, projeto, este, composto por quatro aulas semanais, contendo a duração de cinquenta minutos cada.

Este estudo contou com a participação de, aproximadamente, cinquenta alunos, com faixa etária de cinco a 
sete anos de idade, regularmente matriculadas no primeiro ano do Ensino Fundamental I e, também, com a colaboração de duas professoras efetivas e duas tutoras auxiliares de aula.

O procedimento para a coleta de dados, com o intuito de diagnosticar e analisar as contribuições da Educação Física neste processo de alfabetização, se deu por meio de observação sistematizada, sendo descrita pelos monitores e estagiários participantes do projeto, além de uma entrevista semi-estruturada respondida em forma de questionário aberto pelas professoras e tutoras auxiliares de sala, no qual possuía a seguinte comenda: Mediante as aulas de Educação Física aplicadas durante o ano letivo, descreva quais foram às observações e colocações que vocês, professoras, acharam mais relevantes e importantes. Descreva, também, quais as contribuições que as aulas de Educação Física tiveram quanto ao processo de ensino/aprendizagem.

Vale ressaltar que os sujeitos que participaram da pesquisa autorizaram sua participação a partir da assinatura no termo de consentimento livre e esclarecido, tendo o aval do comitê de ética sob o número de registro: 53201 na data de 07 de Outubro de 2011.

\section{RESULTADOS}

Os resultados das observações apresentadas pelos estagiários e monitores do projeto acabaram relatando que as aulas de Educação Física podem, sim, melhorar o rendimento - seja ele nos seus aspectos cognitivos, afetivos e motores - dentro do ambiente de sala de aula, por consequência da gama de atividades propostas, preparadas e discutidas antes e depois das aulas de Educação Física. Pois acabam envolvendo a interdisciplinaridade e as múltiplas linguagens, pois, dentro dos diversos materiais usados nas aulas, muitos se relacionam com o processo de alfabetização, mostrando, assim, o tanto que esta disciplina pode ser importante na vida das crianças.

Antes do início das aulas de Educação Física, em uma avaliação diagnóstica realizada, as professoras relataram que os alunos apresentavam dificuldades para se expressar e se comunicar, além das dificuldades em compreender os conteúdos propostos nas aulas, dificultando e comprometendo o processo de ensino/aprendizagem. Posteriormente e a partir do início do projeto de extensão com as aulas de Educação Física, as professoras relataram que essas aulas contribuíram e facilitaram muito o trabalho delas em relação ao desenvolver das habilidades, pois as crianças ficaram mais soltas e alegres, apresentando um aumento gradativo e 
significante da aprendizagem e da participação. As atividades propostas pelos monitores e estagiários acabaram despertando, nos alunos, a participação efetiva, a manifestação de suas ideias, dialogando integralmente e melhorando a relação aluno-aluno e aluno-professor. Uma das professoras proferiu a seguinte resposta: "As aulas de Educação Física mediadas durante $\mathrm{o}$ ano letivo contribuíram e melhoraram o respectivo processo, tornando-se de grande valia para o avanço do rendimento escolar e de alfabetização dos nossos alunos" (Professora B).

Nesta análise de cunho qualitativo, observamos que a aprendizagem relatada pelas professoras está ligada tanto à linguagem corporal das capacidades motoras como ao esquema corporal, além de lateralidade e orientação espaço-temporal. Quanto à linguagem oral e escrita, podemos relacionar que o conhecimento do corpo e suas potencialidades podem, de fato, proporcionar uma aprendizagem significativa mediada pela linguagem corporal.

\section{DISCUSSÃO}

Diante dos resultados apresentados, podemos considerar que, durante o processo de alfabetização escolar, a criança tem direito a desfrutar das mais variadas vivências possíveis, sendo estas de fundamental importância para seu processo de formação, e que as aulas de Educação Física colaboram, de forma significativa, nesse processo. Por meio de aulas planejadas, estruturadas e aplicadas, de maneira efetiva e coerente, é possível valorizar os aspectos cognitivos presentes na linguagem corporal, confirmando, assim, que a interação de um bom professor de Educação Física, juntamente com aulas fundamentadas e sistematizadas, podem corroborar de forma ímpar no processo de aprendizagem dos alunos .

Os aspectos motores não podem ser separados do desenvolvimento intelectual, principalmente no que diz respeito à afetividade. Para que o ato de ler e escrever se processe adequadamente, é indispensável - domínio de tais habilidades a ele relacionado. Por isso, o processo de ensino aprendizagem deve ser conduzido de forma interdisciplinar, tendo a Educação Física como suporte para o desenvolvimento pleno do aluno.

O corpo, ao estabelecer relações com os outros, com o meio e com ele mesmo, possibilita o movimento. De acordo com os PCNs (1997), o movimento é uma extensão da formação, do desenvolvimento e da cultura. Sendo assim, o movimento humano constitui-se em uma linguagem que permite às crianças agirem sobre seu meio físico e atuarem sobre o ambiente humano. 
Por meio do movimento e das aulas de Educação Física especificamente voltada para a alfabetização e seus interesses, é possível adequar e conciliar um aprendizado de leitura e escrita de forma lúdica e natural. Garcia (1998) contribui dizendo que:

Se os conteúdos selecionados
para a alfabetização forem
conteúdos extraídos da
necessidade da criança
conhecer-se e conhecer o
mundo à sua volta, a forma,
ou seja, o processo de
trabalhar esses conteúdos, de
possibilitar a apropriação da
leitura e da escrita,
consequentemente, não será
o mesmo. A forma, nesse
caso, deverá garantir as mais
variadas vivências possíveis
com a escrita, no seu uso e
função social (GARCIA, 1998,
p. 91).

Os professores de Educação Física devem, por meio de atividades que desenvolvam noção de tempo, espaço e ritmo, estimular as crianças de maneira prazerosa e desafiadora, enfatizando a verbalização, memória, raciocínio e, principalmente, conferindo sentido a esse processo. Nesse sentido Moyles (2002), salienta que:

Os professores poderão oferecer atividades de linguagem e promover ainda mais o pensamento, ampliar o vocabulário, e talvez começar a conversar com as crianças sobre linguagem. [...] Isso vai incorporar o enriquecimento, a prática, a repetição e a revisão do que foi aprendido através da linguagem, com e sobre ela (MOYLES, 2002, p.67).
Nesse sentido, podemos dizer que a Educação Física e a alfabetização devem caminhar juntas na construção da cidadania e da formação integral da criança; essa relação tende a auxiliar e contribuir no desenvolvimento da leitura/escrita e do corpo. Entretanto, este processo de contribuição deve ser realizado respeitando as peculiaridades individuais e as limitações de cada criança (SILVA; SILVA, 2004).

\section{CONSIDERAÇÕES FINAIS}

É notável que a apreensão da leitura e da escrita é um dos principais objetivos de qualquer instituição, todavia nesta pesquisa nos preocupamos em saber de que maneira isso é solidificado e como é exigido da criança esse crescimento: como puramente leitura e escrita ou como alfabetização de mundo?

Sendo assim, enxergamos a alfabetização como uma abertura de mundo, leitura crítica e consciente e, que para essa transição ocorra de forma favorável e natural, a Educação Física é um componente capaz de acrescentar resultados positivos com um trabalho integrado e comprometido entre professores e escola preocupados em formar integralmente os alunos.

Nessa perspectiva, concluímos, por hora, que com um trabalho integrado da Educação Física pautado nas necessidades características da faixa etária, o processo de alfabetização pode se tornar mais natural, 
envolvente e provocador, com resultados mais expressivos e significativos, não perdendo de vista a ludicidade fundamental para o universo infantil. Pois de acordo com, Taborda de Oliveira (2003, p.158), consideramos “... a educação física um conjunto de saberes primordiais para consignar um projeto de formação humana".

\section{REFERÊNCIAS}

BRASIL. Lei no 9.394/96 - Lei de diretrizes e bases da educação Nacional. Brasília: Ministério da Educação e Cultura, 1996.

BRASIL. Secretaria de Ensino Fundamental. Parâmetros curriculares Nacionais: Educação Física. Brasília: Ministério da Educação, 1997.

CAGLIARI, L. C. Alfabetizando sem o ba-bébi-bó-bu. São Paulo: Scipione, 1999.

FEDERICI, C.A.G. O que não é educação física. Revista Movimento \& Percepção, Espírito Santo de Pinhal, SP, v.4, n.4/5, jan./dez. 2004.

FERREIRO, E. Reflexões sobre alfabetização. São Paulo: Cortez, 2000. . Alfabetização e cultura escrita.

Revista do Professor. Nova Escola, São Paulo, maio, 2003.

FREIRE, P. Conscientização: teoria e prática da libertação: uma introdução ao pensamento de Paulo Freire. 3. ed. São Paulo: Centauro, 2001.

GARCIA, R, L (org.). A Formação da professora alfabetizadora: reflexões sobre a prática. 2. ed. São Paulo: Cortez, 1998.

KRAMER, S.; ABRAMOVAY, M. Alfabetização na pré-escola: exigência ou necessidade.
Cadernos de Pesquisa, São Paulo, n. 52, p. 103-107, fev. 1985.

LAKATOS, E. M. Fundamentos de metodologia científica. São Paulo: Atlas, 1990.

LIBÂNEO, J. C.; OLIVEIRA, J. F. de; TOSCHI, M. S.. Educação escolar: políticas, estrutura e organização. São Paulo: Cortez, 2003.

MACEDO, R.L.; ANTUNES, R.C.F. Valoração da educação física: da produção acadêmica ao reconhecimento individual e social. Pensar a Prática, Goiânia, v.2, n.1, p.65-83, 1998/1999.

MOYLES, J, R. Só brincar? - 0 papel do brincar na educação infantil. São Paulo: Artmed, 2002.

SILVA, A, P, da; SILVA, J, L. Alfabetização e Educação Física escolar caminho juntas rumo à cidadania. Revista do mestrado da UFS, $v$. 8, 2004.

TABORDA DE OLIVEIRA, M. A.; VILLA, M. E. Educação Física, corporalidade e escola. In: Valter Bracht; Ricardo Crisório. (Org.). A Educação Física no Brasil e na Argentina: identidade, desafios e perspectivas. Campinas: Autores Associados, 2003, v. 1, p. 147-154.

Recebido para publicação em 22/05/2015 Revisado em 02/07/2015 Aceito em 15/07/2015 